\title{
Mixing Effect of Anionic and Nonionic Surfactants on Micellization, Adsorption and Partitioning of Nonionic Surfactant
}

\author{
Mazen Ahmed Muherei (Corresponding author) \\ Department of Petroleum Engineering, FKKKSA, UTM \\ 81310 Skudai, Johor, Malaysia \\ Tel: 60-17-768-3487_E-mail: mazen_moherey@yahoo.com \\ Radzuan Junin \\ Department of Petroleum Engineering, FKKKSA, UTM \\ 81310 Skudai, Johor, Malaysia \\ Tel: 60-19-789-9703 E-mail: radzuan@fkkksa.utm.my
}

\begin{abstract}
Nonionic surfactants are always good candidates for surfactant enhanced aquifer remediation (SEAR), enhanced oil recover (EOR) and insitu/ex-situ soil washing. Their wide application is based on their high solubilization capacities and their low bio-toxicity. However, surfactant loss due to adsorption and/or partitioning on adsorbents impairs their effectiveness to solubilize/mobilize and reduce the oil-water interfacial tension (IFT) which renders contaminant remediation process economically unfeasible. In this research anionic (SDS) and nonionic (TX100) surfactants and their mixtures $(1: 2,1: 1,2: 1$; TX100:SDS mass ratios) were evaluated for their ability to reduce surfactant CMCs, partitioning losses to an organic phase and/or adsorption to shale. Result showed that all mixtures behave similarly and have superior properties than both single surfactants. Partitioning and adsorption of TX100 into organic phase (Sarapar147) and shale were decreased by mixing with anionic surfactant (SDS). The data showed a $40 \%$ reduction in surfactant losses due to adsorption to shale and around $60 \%$ reduction due to both partitioning and adsorption.
\end{abstract}

Keywords: Surfactant, CMC, Surface tension, Interfacial tension, Adsorption, Partition, Mixed surfactants

\section{Introduction}

The use of surfactants to decontaminate groundwater aquifers, facilitate/enhance residual oil recovery and in soil-clean up operations is well established, and both anionic and nonionic surfactants have been used to remediate land polluted with oils and hydrocarbons as well as many other organic contaminants. The most important parameter in terms of the ability of a surfactant to mobilize or solubilize hydrophobic contaminants in contaminated soil is the surfactant critical micelle concentration (CMC). In general, concentrations of surfactant in soil-water below the CMC have little or no effect on solubilization of hydrophobic materials. Only when micelles are present does significant desorption of such pollutants from soil surfaces occur (Haigh, 1996).

Nonionic surfactants are often used because of their lower CMCs as compared to ionic surfactants, their higher degree of surface-tension reduction, and their relatively constant properties in the presence of salt, which result in better performance and lower concentration requirements. In particular, the non-ionic ethoxylate surfactants have been suggested for the removal of organic contaminants from soil because of their high solubilization capacity and biodegradability (Kile and Chiou, 1989; Zhou and Rhue, 2000; Paria and Yuet, 2007). However, some concerns with these surfactants are their significant loss to soil and partitioning to organic phase during practical applications (Butler and Hayes, 1998; Zimmerman et al., 1999; Cowell et al., 2000; Zhao et al., 2006; Zhao et al., 2007). Nevertheless, under some conditions, usually at concentration well below CMC, the adsorption of these surfactants to soil can enhance the adsorption of hydrophobic contaminants to soil. This has been attributed to partition of hydrophobic contaminants into surfactant hemi-micelle formed on soil surface (Edwards et al., 1994; Sun et al., 1995; Haigh, 1996).

Anionic surfactant on the other hand, sorb less to soil but they form micelles at higher concentrations in aqueous solutions than nonionic surfactants with an equivalent hydrophobic group (Rosen, 2004) and are more prone to precipitate in presence of multivalent cations $\left(\mathrm{Ca}^{++}, \mathrm{Mg}^{++}\right)$. Substantial loss of surfactant by such mechanisms will definitely reduce their active concentration in aqueous solution, which would greatly reduce the surfactant solubilization and flushing efficiency. 
Use of well designed surfactant mixtures may greatly alleviate those problems. A typical feature of ionic (anionic/cationic)-nonionic mixtures is the synergy or anti-synergism (antagonism) at interfaces. For example, the adsorption of one surfactant is either enhanced or retarded by the addition of a small amount of the other surfactant. Furthermore, mixing ionic and nonionic surfactants may raise or lower the CMC from that obtained by ideal mixing.

Generally, several studies had investigated surfactant mixtures of nonionic and anionic surfactants. Most of these studies focused on synergism in critical micelle concentration obtained upon mixing (Janczuk et al., 1995; Owoyomi, 2005; Joshi et al., 2005; Zhang et al., 2005; Mata, 2006; Zhao and Zhu, 2006; Zhao et al., 2006). Other studies deal with solubilization of organic compounds in anionic-nonionic surfactant mixtures (Zhu and Feng, 2003; Zhou and Zhu, 2004; Zhao et al., 2005; Zhou and Zhu, 2005; Zhao and Zhu, 2006; Zhao et al., 2006; Zhao et al., 2007). Several studies deal also with remediation of soil contaminated with specific contaminants (Lee et al., 2004; Zhou and Zhu, 2007; Yu et al., 2007).

Although the adsorption of single surfactants at the solid-liquid interface has been studied intensively, far fewer studies exist for the case of adsorption from mixed surfactant solutions. Adsorption of anionic-nonionic surfactant mixtures on positively and negatively charged surfaces were reported (Wang and Kwak, 1999 [TX100-SDS to positively charged alumina]; Porcel et al., 2001 [TX100-SDS to positively and negatively charged polystyrene latexes]; Yang et al., 2005 [TX100-SDBS to Ca-montmorillonite]; Rao and He, 2006 [SDBS- $\mathrm{A}_{12} \mathrm{E}_{9}$ to natural soil]). Accordingly, it is not surprising that only a very few studies have been reported for adsorption of anionic-nonionic surfactant in natural soils and in presence of oil phase.

Generally, researchers found that the CMCs of mixed anionic-nonionic surfactants were lower than those of sole anionic surfactants. Furthermore, with the increase in mole fraction of the nonionic surfactant, the CMCs decrease continuously from the $\mathrm{CMC}$ of pure anionic surfactant down to the $\mathrm{CMC}$ of pure nonionic surfactant. The experimental CMCs were found lower than the ideal mixing CMCs (Janczuk et al., 1995; Zhu and Feng, 2003; Zhou and Zhu, 2004; Owoyomi, 2005; Zaho et al., 2005; Joshi et al., 2005; Yang et al., 2005; Zhang et al., 2005; Zhao et al., 2006; Zhao et al., 2007).

For the adsorption case of anionic-nonionic surfactant mixtures, which surfactant is adsorbed preferentially depends on the nature and charge of mineral surface. For positively charged surfaces to which anionic surfactants are heavily adsorbed, presence of nonionic surfactant decreases adsorption of anionic surfactant and the adsorption of nonionic surfactant is enhanced where nonionic alone shows trace adsorption (Wang and Kwak, 1999; Paria and Khilar, 2004). On the other hand, for clay minerals that shows affinity to nonionic surfactant, presence of anionic surfactant retard nonionic surfactant adsorption (Paria and Khilar, 2004; Yang et al., 2005).

Recently, mixed nonionic and anionic surfactants were investigated for their abilities to retard non-ionic surfactant sorption and partition to soil and organic phase, respectively. Researchers found mixtures superior to the relevant single ones mainly due to the reduction in nonionic surfactant partition and/or sorption to soil as well as the high solubilization capacity of the mixture. Yang et al. (2005) showed that the amounts of both Triton X100 (TX100) and sodium dodecylbenzene sulfonate (SDBS) sorbed to Ca-montmorillonite are significant. However, the amount of either surfactant sorbed can be decreased and minimized when they are mixed with each other. Furthermore, the extent of the nonionic surfactant (TX100) which partition into the organic phase was found to decrease if the amount of the anionic surfactant (SDBS) increased (Zhao et al., 2006; Zhao et al., 2007). Decreasing loss of surfactant due to partitioning and/or sorption and the greater apparent solubilization of the mixture will reduce surfactants volumes needed and thus the capital expenditure and operation cost (Zhao and Zhu, 2006).

Accordingly, it becomes impressive to investigate the ability of nonionic-anionic surfactants mixtures to reduce CMCs and surfactant losses either by reducing partition to organic phase or adsorption to soil or sediments at different experimental conditions, i.e. different sorbent and different organic phase. This study is intended to investigate the simultaneous losses of sodium dodecyl sulfate (SDS), TX100 and their mixtures by partitioning, adsorption and abstraction. The study will investigate the adsorption of SDS, TX100 and their mixtures to Batu Arang's shale. Surface tensions of surfactants and their mixtures are studied to determine adsorption and micellization properties. Interfacial tensions of surfactants and their mixtures with an oil phase, Sarapar147 are also studied to investigate simultaneous surfactant partitioning, adsorption and micellization.

SDS and TX100 have been selected mainly because they are frequently used by the industry and are then readily available and well priced. Furthermore, both surfactants have been the most extensively studied surfactants from the anionic and nonionic classes, respectively (Mata, 2006). Both surfactants were found successful in the extraction of organic contaminants from soils (Chou et al., 1998; Deshpande et al., 1999; Sanchez-Camazano et al. 2000; Chang et al., 2000; Jada and Hamieh, 2001; Zhang et al., 2001; Chu and Chan, 2003; Sanchez-Camazano et al., 2003; Sanchez-Martin et al., 2003; Rodriguez-Cruz et al., 2004; Saichek and Reddy, 2004; Smith et al., 2004; Urum et al., 2004; Urum and Pekdemir, 2004; Rodriguez-Cruz et al., 2006; Urum et al., 2006). 


\section{Materials}

\subsection{Surfactants}

Triton X-100 (TX100) extra pure, was purchased from Scharlau Chemie, Spain. Sodium dodecyl sulfate (SDS) was obtained from Merck with a high grade of purity (99\%). The oil, Sarapar147, was supplied by Kota Minerals and Chemical Sdn. Bhd. (KMC). Sarapar147 is a colourless mineral oil ranging from C14 to C17 and is derived from petroleum crude oil. All chemicals were used as received without further purification. Selected physicochemical properties of the compounds are presented in Table 1.

\subsection{Shale Samples}

Samples were collected from an outcrop of a local shale formation (Batu Arang, Selangor, Malaysia). Rock samples were disintegrated into small pieces by a jaw crusher and then ground using rock pulverizer (Fritsch, Germany). Rock samples were air dried for $24 \mathrm{hrs}$ followed by oven drying at $105^{\circ} \mathrm{C}$ for $24 \mathrm{hrs}$. Density of shale was determined to be $1.94 \mathrm{~g} / \mathrm{cc}$. Dried rock samples were sieved to obtain particles less than $2 \mathrm{~mm}$ and larger than $1 \mathrm{~mm}$ in all experiments.

\section{Methods}

\subsection{Preparation of Surfactant Solutions}

The surfactant solutions were prepared in a standard $1000 \mathrm{~mL}$ volumetric flasks. Surfactants were weighed on mass basis and emptied into the volumetric flask and then double distilled water was used to complete the solution to the final weight $(1 \mathrm{Kg})$. After the preparation of the stock solution, it was diluted to obtain desired concentration.

TX100 and SDS solutions were prepared at concentrations ranges from $0.0025 \mathrm{wt} \%$ to $1 \mathrm{wt} \%$ corresponding to molar concentrations of $0.039-15.47 \mathrm{mM}$ for TX100 and $0.0867-34.68 \mathrm{mM}$ for SDS. Mixed surfactant solutions were prepared by mixing SDS and TX100 solutions of the same weight concentrations with different volume ratios $(2: 1,1: 1$, and 1:2 SDS:TX100). This results in a mole fraction of SDS in the total mixtures of $0.82,0.69$ and 0.53 , respectively. Mixed surfactant solutions were allowed to equilibrate for at least $5 \mathrm{hrs}$ before any measurements were made.

\subsection{Surface Tension Measurements}

The surface tension technique was applied to determine the CMC in various combinations of shale and/or surfactant systems. The surface tension measurements were carried out with Krüss tensiometer (Krüss GmbH, Hamburg, Instrument $\mathrm{Nr}$, K6) using a platinum-iridium ring at constant temperature $\left(25 \pm 1^{\circ} \mathrm{C}\right)$. The tensiometer was calibrated using method described in ASTM Designation: D1331-89. Surface and interfacial tension measurements were undertaken according to the method described in ASTM Designation: D1331-89.

Krüss tensiometer operates on the $\mathrm{Du}$ Nouy principle, in which a platinum-iridium ring is suspended from a torsion balance, and the force (in $\mathrm{mN} / \mathrm{m}$ ) necessary to pull the ring free from the surface film is measured. Surface tension value was taken when stable reading was obtained for a given surfactant concentration, as indicated by at least three consecutive measurements having nearly the same value. The average of a series of consistent readings for each sample was then corrected to account for the tensiometer configuration, yielding a corrected surface tension value (Zuidema and Waters, 1941). A correction factor, F, is multiplied by the average dial reading in order to obtain the corrected value for surface/interfacial tension (ST/IFT). Zuidema and Waters (1941) proposed the following empirical correlation to calculate the correction factor:

$F=0.725+\sqrt{\left[\frac{9.075 \times 10^{-4}(\text { STorIFT })}{\pi^{3} \Delta \rho g R^{3}}-\frac{1.679 r}{R}+0.04534\right]}$

Where $F=$ the correction factor; $R=$ the radius of the ring, $\mathrm{cm} ; r=$ the radius of the wire of the ring, $\mathrm{cm} ; \mathrm{ST} / \mathrm{IFT}=\mathrm{the}$ apparent value or dial reading, dyne/cm $(\mathrm{mN} / \mathrm{m}) ; \Delta \rho=$ the density difference between the lower and upper phases, $\mathrm{g} / \mathrm{cc}$; $g=$ acceleration due to gravity, $980 \mathrm{~cm} / \mathrm{sec}^{2}$. The Equation is applicable only when $0.045 \leq \Delta \rho g R 3 /(S T$ or IFT) $\leq 7.5$

\subsection{Interfacial Tension Measurements}

Equal volume $(15 \mathrm{~mL})$ of Sarapar147 and surfactant solution was poured into a glass beaker of $6 \mathrm{~cm}$ diameter and the resulting mixture used for the interfacial tension studies. The same procedure used for the surface tension measurement was used for the interfacial tension study except that the balance of the tensiometer reading for zero was checked with the platinum-iridium ring completely immersed in the surfactant solution phase and not in the surface or interface of Sarapar147-surfactant. Hence, the platinum ring must be completely immersed in the surfactant phase before the platform is gradually adjusted until a force necessary to detach the platinum ring upward from the surfactant-oil interface is exerted.

\subsection{CMC Measurements}

The CMC values were obtained through a conventional plot of the surface/interfacial tension versus the surfactant concentration. The $\mathrm{CMC}$ concentration corresponds to the point where the surfactant first shows the lowest surface/interfacial tension. The surface/interfacial tension remains relatively constant after this point. 


\subsection{Adsorption to Shale}

Adsorption isotherms were determined by batch equilibrium adsorption procedures. $10 \mathrm{~g}$ of shale were added to a set of $60 \mathrm{~mL}$ surfactant solutions (surfactant initial concentrations spans from $0.0025 \mathrm{wt} \%$ to $1 \mathrm{wt} \%$ ) in a $100 \mathrm{~mL}$ glass vials $(1: 6$ $\mathrm{w} / \mathrm{v}$ ratio) and allowed to equilibrate at $25 \pm 1{ }^{\circ} \mathrm{C}$. The surfactant solution-to-soil ratio was designated as $6: 1(\mathrm{v} / \mathrm{w})$ to reach the optimal washing performance (Chu and Chan, 2003; Urum and Pekdemir, 2004). The vials were then agitated on a gyratory shaker at 100rpm (wrist orbital shaker) for $3 \mathrm{hrs}$ and allowed to rest for 16hrs. Surfactant sample aliquots were taken for surfactant concentration determination before and after adsorption. All experiments were conducted with 3 replicates at $25 \pm 1^{\circ} \mathrm{C}$. To determine the maximum sorption of surfactants into shale, a surface/interfacial tension method was used. Each adsorption experiment involved 10 batch test samples in $100 \mathrm{~mL}$ glass vials. The amount of surfactant adsorbed and/or abstracted was computed from the difference of CMC values before and after adsorption, and means of three replicates were used.

\section{Results and Discussion}

\subsection{Surfactant Partition into Sarapar147}

Figures 1 and 2 illustrate a typical graph of surface/interfacial tensions against the logarithm of the surfactant dose for fresh solutions. Figure 1 shows surface tensions (STs) while Figure 2 shows interfacial tensions (IFTs). The Figures depict the surface/interfacial tension curves as total surfactant concentration for the mixed SDS-TX100 system in which the molar fractions of SDS are 1, 0.82, 0.69, 0.53 and 0, respectively. Surface tension between water and air was measured as $72.57 \mathrm{mN} / \mathrm{m}$ while interfacial tension between water and Sarapar147 was found as $29.64 \mathrm{mN} / \mathrm{m}$. As the surfactant solution is introduced, this value was reduced. As shown in Figures 1 and 2, surface/interfacial tension is concentration dependent. As the surfactant concentration increases, surface/interfacial tension decreases until the surfactant $\mathrm{CMC}$ value is reached and remains relatively constant there after wards.

CMC of pure surfactants obtained were compared with those in literature. CMC values of SDS obtained from both surface/interfacial tensions vs. concentration are similar at $0.1 \mathrm{wt} \%(3.468 \mathrm{mM} / \mathrm{L}$ or $1000 \mathrm{mg} / \mathrm{L})$ indicating minor losses of this surfactant to oil phase (Sarapar147). CMC of SDS compares well with those reported in Zhu and Feng (2003), Zhou and Zhu (2004), Zhao et al., (2005) and Zhou and Zhu (2007).

The CMC values of TX100 obtained by surface tension measurements (Figure 1) were much lower than that obtained by interfacial tension measurements (Figure 2$)$. The first value $(0.025 \mathrm{wt} \%)$ was comparable well with values reported in previous published studies (Zhu and Feng, 2003; Zhou and Zhu, 2004; Zhao et al., 2005; Zhou and Zhu, 2007). The second value $(0.07 \mathrm{wt} \%)$, however, was not reported in literature. This is because surface tension technique is often used to determine surfactant CMCs and hence the effect of oil in micellization is ignored. It is rather noteworthy that it is the interfacial tension which is valuable to practical processes and not surface tension. Hence, reporting CMCs using surface tension technique may lead to misleading results. The difference in $\mathrm{CMCs}(0.045 \mathrm{wt} \%$ or $0.45 \mathrm{~g}-\mathrm{TX} 100 / \mathrm{L}-$ Sarapar147) may be due to partitioning of TX100 into Sarapar147 which result in loss of some active monomers of TX100.

Zhao et al. (2006 and 2007) reported extensive losses of TX100 due to partitioning into the organic phase, however no SDBS partitioning was found. Losses of TX100 with an initial concentration of $10 \mathrm{~g} / \mathrm{L}(1 \mathrm{wt} \%)$ into Trichloroethene, Chlorobenzene, 1,2-Dichlorobenzene and Tetrachloroethene phases were more than 99\%, 97\%, 97\%, and 15\%, respectively when single TX100 was used. They attributed this behavior to the formation of reverse micelles (nonpolar exterior, polar interior) at lower IFTs. The affinity of TX100 to partition increased if the organic phase is polar.

As shown in Figures 1 and 2, the surface/interfacial tensions of mixed surfactants at a given molar ratio decreased with increasing total surfactant concentration. Each surface/interfacial tension curve had a breaking point that was taken as a mixed CMC. The CMCs of the mixtures as determined by surface tension curves are similar and very close to that of pure TX100 determined by surface tension curves (Figure 1). This is generally in agreement with other studies (Zhao et al., 2005; Mata, 2006). The CMCs of surfactants mixtures as determined by interfacial curves (Figure 2) are also nearly similar to pure TX100's CMC determined by surface tension curves, however, they are much lower than that of pure TX100 $(0.07 \mathrm{wt} \%)$ determined by interfacial curves. Therefore, mixtures have eliminated surfactant loss through partitioning. Zhao et al. (2006 and 2007) reported similar findings and found that partitioning of TX100 into nonaqueous phase liquids decreased by mixing with anionic surfactant (SDBS). This trend was attributed to the less affinity of anionic surfactant to partition into the organic phase and the formation of mixed micelles.

\subsection{Surfactant Adsorption to Shale}

Surfactant adsorption to solid surfaces is a process of transfer of surfactant molecules from bulk solution phase to the surface of the solid surface (Paria and Khilar, 2004). Adsorption can also be considered as a partitioning of the surfactant monomers between the solid surface and the bulk, and can occur if the solid surface is energetically favored by the surfactant in comparison to the bulk solution. Generally, adsorption of surfactants and their mixtures at solid/solution interface is a complex process. The driving force for adsorption is a combination of the electrostatic 
interaction, the chemical interaction, the lateral chain-chain associative interaction, the hydrogen bonding and desolvation of the adsorbate species (Zhang and Somasundaran, 2006).

As seen in Figure 3, surface tensions for SDS have not been changed before and after equilibration with shale (SDS=b \& SDS $=a$, respectively). However, surface tensions for TX100 were increased significantly after equilibration with shale $(\mathrm{TX}=\mathrm{a})$. Similarly, the CMC of both SDS and TX100 as determined by surface tension technique are different at $0.1 \mathrm{wt} \%$ and $1.5 \mathrm{wt} \%$, respectively. Hence, the CMC of SDS has not been notably changed before and after equilibration with shale. This indicates a minor loss of this surfactant to shale. In contrast, the CMC value of TX100 has been shifted to higher concentrations, i.e., the surfactant was adsorbed heavily to shale. This is a result of less surfactant monomer concentration in surfactant solutions after equilibration with shale. This significant loss of TX100 monomers is attributed to their adsorption to organic matter/clay minerals in shale.

Figure 4 depicts surface tension curves of individual surfactants and their mixtures after equilibration with shale. It is obvious that mixtures at all SDS molar fractions do improve behavior of individual surfactants at air-water interface. All CMCs of SDS-TX100 mixtures are similar to that of pure SDS at $0.1 \mathrm{wt} \%$ and lower than that of pure TX100 $(0.15 \mathrm{wt} \%)$.

At the CMC values, the concentration of the bulk solutions will be saturated with surfactant monomers. As the fresh surfactant solution start to form micelles at a specific monomer concentration, it is assumed that surfactant/shale supernatant would form micelles at the same monomer concentration indicating the same surface/interfacial tension but at different CMCs. Hence, the amount of surfactant adsorbed to shale can be calculated from difference between CMC obtained after equilibration with shale and/or presence of oil phase and the original CMC. From Figure 3, the difference in pure TX100's CMCs as determined from surface tension curves was found to be $0.125 \mathrm{wt} \%(0.15-0.025 \mathrm{wt} \%)$. This concentration can be normalized to shale mass by dividing it by sorbent mass and multiplying by solution mass to yield $\mathrm{g}$-TX100 to g-Shale $(0.00125 \times 60 / 10 \mathrm{~g}=0.0075 \mathrm{~g}-\mathrm{TX} 100 / \mathrm{g}$-shale or $7.5 \mathrm{~g}$-TX100/Kg-shale). Similar values have been reported in literature for natural soil (Zheng and Obbard, 2002; Zhou and Zhu, 2007). Zheng and Obbard (2003) found a maximum loss of 5mmole-TX100/Kg-soil (3.14g-TX100/Kg-soil). Similarly, Zhou and Zhu (2007) reported a maximum loss of about $12 \mathrm{mmole}-\mathrm{TX} 100 / \mathrm{Kg}$ soil $(7.536 \mathrm{~g}-\mathrm{TX} 100 / \mathrm{Kg}$-soil) to an uncontaminated soil collected from Hangzhou City, China.

Considering the surface tension trends (Figures $1 \& 4$ ), CMCs of mixtures were close to TX100 CMC before equilibration with shale and closer to SDS's CMC after equilibration with shale. Hence, the maximum adsorption for mixtures $(\triangle \mathrm{CMC}=0.1-0.025=0.075 \mathrm{wt} \%)$ are lower than that of pure $\mathrm{TX} 100(\Delta \mathrm{CMC}=0.15-0.025=0.125 \mathrm{wt} \%)$, i.e. $40 \%$ reduction. Accordingly, it can be said that the presence of SDS (at molar ratios used in this work) did reduce sorption of TX100 to shale. This is in agreement with the observation made by other researchers (Zhou and Zhu, 2007; Yu et al., 2007). Zhou and Zhu (2007) found a $45-71 \%$ (from 11.6 to 6.41 and $3.33 \mathrm{mM} / \mathrm{Kg}$ ) decrease in the maximum sorption amount of TX100 while using approximately comparable SDS molar ratios as this study (1:2 and 2:1 SDS:TX100 mass ratio, respectively). Yu et al. (2007) results showed $47-70 \%$ (from 15 to 8 and $4.5 \mathrm{mM} / \mathrm{Kg}$ ) reduction with 1:2 and 2:1 SDS:TX100 mole ratios, respectively.

Generally, the nature of solid surface whether hydrophobic or hydrophilic and the electrical interactions play an important role in the kinetics of adsorption of surfactant at the solid-liquid interface. Electrostatic interactions are most important for anionic SDS surfactant. Most natural surfaces are negatively charged under naturally occurring conditions. As a result, anionic surfactant will experience a repulsive electrostatic interaction with most natural surface; this serves to make them adsorb to a lesser extent than nonionic surfactants for most applications. Adsorption of a nonionic surfactant such as TX-100 has proposed to involve hydrogen bonding. Hydrogen bonding is weaker than electrostatic interactions. It should be noted that for adsorption due to hydrogen bonding to take place, the bond formed between the surfactant functional groups and mineral surfaces should be stronger than that formed between the mineral and interfacial water molecules (Zhang and Somasundaran, 2006). Hydrophobic bonding can also be important for adsorption on solids that possess a fully or partially hydrophobic surface. In this case, surfactant molecules can adsorb flat on the hydrophobic sites on the solid. Such adsorption can also take place on other types of solids that are originally hydrophilic, but that have acquired some hydrophobicity owing to reaction with organic species in solutions (Somasundaran and Huang, 2000).

More importantly, surfactant adsorption is related to the chemical potential of the surfactant molecules (monomers) in solution and the nature of the solid. Under mixed micellization conditions the chemical potential of monomers will be lower than that for the single surfactant system and this in turn can reduce adsorption at the solid-liquid interface. Beyond the $\mathrm{CMC}$, the aqueous monomer concentration will not increase with any further addition of surfactant since the additional surfactant will form micelles. Sorption of TX100 surfactant as well as SDS-TX100 mixtures to shale is limited by their critical micelle concentrations and reaches a plateau at their CMCs. The CMC-limited sorption of surfactants reflects the significant effects in reducing the CMC of surfactant system; in other words, a reduction in their CMCs reduces their sorption to shale. 


\subsection{Surfactant Losses to Both Shale and Oil}

After equilibration with shale and in presence of oil phase, SDS interfacial tension $\left(\mathrm{SDS}=\mathrm{a}^{+}\right)$has been slightly increased particularly for sub-micellar concentrations (Figure 5). Meanwhile, Interfacial tensions for TX100 were increased significantly $(\mathrm{TX}=\mathrm{a}+)$. This significant loss of TX100 is attributed to adsorption to organic matter/clay minerals in shale and partitioning into Sarapar147.

CMC of TX100 was attained at $0.25 \mathrm{wt} \%$ in presence of Sarapar147. This is a perceptible detrimental change in TX100 behavior in presence of both shale and oil. The result shows that both shale and Sarapar147 are responsible for loss of TX100. As shown in Figure 5, the difference in CMCs of pure TX100 as determined from interfacial tension curves was found to be $0.225 \mathrm{wt} \%(0.25-0.025)$. When normalized to mass of shale and solution a value of $22.5 \mathrm{~g}$-TX100/Kg-shale can be estimated. This tremendous loss of TX100 surfactant concentration is due to interaction of TX100 with both shale and Sarapar147.

As shown in Figure 6, surfactant mixtures performed better in presence of both shale and oil. Though the CMCs and interfacial tensions are not lower than those of pure SDS' CMC $(0.1 \mathrm{wt} \%)$, they are however, much lower than that of pure TX100 $(2.5 \mathrm{wt} \%)$. Mixtures result in about $60 \%$ reduction in surfactant losses. Hence, it can be said that the presence of SDS significantly reduced adsorption and partitioning of TX100 to shale and Sarapar147, respectively.

It is clear that the addition of SDS has reduced the amount of TX100 adsorbed to shale or partitioned into the oil phase. It is widely accepted among researchers that SDS surfactant is less likely to adsorb to shale and far less likely to partition into an oil phase. However, TX100 surfactant is more liable to sorb onto shale and partition into oil phase (Harusawa et al., 1980; Butler and Hayes, 1998; Zimmerman et al., 1999; Cowell et al., 2000; Zhao et al., 2006; Zhao et al., 2007). Mixing SDS with TX100 may therefore retard the affinity of TX100 to sorb onto shale or partition into oil phase. It is needed to point out that sorption and/or partitioning of any surfactant proceeds through the sorption and/or partitioning of surfactant monomers and micelle formation limits surfactant adsorption and partitioning, i.e., the micelles are not directly sorbed or partitioned (Harusawa et al., 1980; Zhu et al., 2003; Paria and Khilar, 2004). In mixed surfactant solution, the formation of mixed micelles affect the CMC, i.e. mixing will result in a lower CMC. This will reduce the monomer concentration of component surfactant in mixed solution and hence their sorption onto shale and partition to oil phase (Zhou and. Zhu, 2007).

\section{Conclusion}

The choice of a successful surfactant to enhance remediation must goes beyond selection of surfactant system that efficiently solubilize or mobilizes specific oil contaminants. The surfactant must also be matched to the subsurface soil matrix and salinity conditions. Similarly, surfactant partition tendencies into the specific oil contaminants must be addressed. This may ensure that the surfactant system remains at an active concentration. Surfactants losses to soils and/or oil phase will, through various chemical interactions such as sorption, precipitation and partitioning retard contaminant removal. Surfactant sorption to soil will increase soil/sediment organic carbon content favoring the adsorption of hydrophobic organic compounds, escalate cost of the operation by increasing surfactant doses let alone surfactant pollution to soil/ground water and their effect on contaminant biodegradation.

Attempts made in this work to minimize losses of nonionic surfactant (TX100) to local shale and/or partitioning to oil, Sarapar147, through use of anionic-nonionic (SDS-TX100) surfactant mixture was successful. SDS-TX100 surfactant mixtures were able to maintain their active concentrations in presence of shale and oil while using low initial surfactant concentration as low as $0.1 \mathrm{wt} \%$. The experimental data from surface tensions of solutions before equilibration with shale showed that CMCs of mixed surfactants are much lower than that of individual SDS but closer to that of pure TX100. However, data from interfacial tensions showed that CMCs of mixed surfactants are lower than both surfactants. After equilibration with shale the CMCs of mixtures as obtained from surface and interfacial tension data are close to that of pure SDS $(0.1 \mathrm{wt} \%)$ but are much lower than that of pure TX100 (1.5 and $0.25 \mathrm{wt} \%$, respectively). Results showed that all mixtures behave similarly and have superior properties than both single surfactants. Partitioning and adsorption of TX100 into organic phase (Sarapar147) and shale were decreased by mixing with anionic surfactant (SDS). The data showed a $40 \%$ reduction in surfactant losses due to adsorption to shale and around $60 \%$ reduction due to both partitioning and adsorption.

\section{References}

Butler, E. C., \& Hayes, K. F. (1998). Micellar solubilization of nonaqueous phase liquid contaminants by nonionic surfactant mixtures: effects of sorption, partitioning and mixing. Water Research, 32, 1345-1354.

Chang, C.-R., Huang, C.-R., \& Shu, H.-Y. (2000). Effect of surfactants on extraction of phenanthrene in spiked sand. Chemosphere, 41, 1295-1300.

Chou, C. C., Ososkov, V., Zhang, L., \& Somasundaran, P. (1998). Removal of nonvolatile hydrophobic compounds from artificially and naturally contaminated soils by column flotation. Journal of Soil Contamination, 7, 5, 559-571. 
Chu, W., \& Chan, K. H. (2003). The mechanism of the surfactant-aided soil washing system for hydrophobic and partially hydrophobic organics. The Science of the Total Environment, 307, 83-92.

Cowell, M. A., Kibbey, T. C. G., Zimmerman, J. B., \& Hayes, K. F. (2000). Partitioning of ethoxylated nonionic surfactants in water/NAPL systems: effects of surfactants and NAPL properties. Environ. Sci. Technol., 34, 1583-1588.

Deshpande, S., Shiau, B. J., Wade, D., Sabatini, D. A., \& Harwell, J. H. (1999). Surfactant selection for enhancing ex situ soil washing. Water Research, 33, 351-360.

Edwards, D. A., Adeel, Z., \& Luthy, R. G. (1994). Distribution of nonionic surfactant and phenanthrene in a sediment/aqueous system. Environ. Sci. Technol., 28, 1550-1560.

Haigh, S. (1996). A review of the interaction of surfactants with organic contaminants in soil. The Science of the Total Environment, 185, 161-170.

Harusawa, F., Taeko, S., Nakajima, H., \& Fukushima, S. (1980). Partition isotherms of nonionic surfactants in the water-cyclohexane system and type of emulsion produced. Journal of Colloid and Interface Science, 74, 435-440.

Jada, A., \& Hamieh, T. (2001). Removal by surfactants of asphalt adsorbed onto clays. IEEE, 154-158.

Janczuk, B., Bruque, J. M., Gonzalez-Martin, M. L., \& Doradu-Calasanz, C. (1995). The properties of mixtures of ionic and nonionic surfactants in water at the water/air interface. Colloids and Surfaces A: Physicochemical and Eng. Aspects, 104, 157-163.

Joshi, T., Mata, J., \& Bahadur, P. (2005). Micellization and interaction of anionic and nonionic mixed surfactant systems in water. Colloids and Surfaces A: Physicochem. Eng. Aspects, 260, 209-215.

Kile D. E., \& Chiou C. T. (1989). Water solubility enhancement of DDT and trichlorobenzene by some surfactants below and above the critical micelle concentration. Environ. Sci. Technol., 23,832-838.

Lee, D. H., Chang, H. W., \& Cody, R. D. (2004). Synergism effect of mixed surfactant solutions in remediation of soil contaminated with PCE. Geosciences Journal, 8, 3, 319-323.

Mata, J. P. (2006). Hydrodynamic and clouding behavior of Triton X-100 + SDS mixed micellar systems in the presence of sodium chloride. Journal of Dispersion Science and Technology, 27, 49-54.

Owoyomi, O., Jide, I., Akanni, M. S., Soriyan, O. O., \& Morakinyo, M. K. (2005). Interaction between sodium dodecylsulphate and Triton X-100: molecular properties and kinetics investigations. Journal of Applied Science, 5, 4, 729-734.

Paria, S., Manohar, C., \& Khilar, K. C. (2003). Experimental studies on adsorption of surfactants onto cellulosic surface and its relevance to detergency. Journal of the Institution of Engineers, Singapore, Vol. 43, No. 2, 34-44.

Paria, S., \& Yuet, P. K. (2007). Adsorption of nonionic surfactants onto sand and its importance in naphthalene removal. Ind. Eng. Chem. Res., 46,108-113.

Porcel, R., Jodar, A. B., Cabrerizo, M. A., Hidalgo-Albarez, R., \& Martin-Rodriguez, A. (2001). Sequential adsorption of Triton X-100 and sodium dodecylsulfate onto positively and negatively charged polystyrene latexes. Journal of Colloid and Interface Science, 239,568-576.

Rao, P., \& He, M. (2006). Adsorption of anionic and nonionic surfactants mixtures from synthetic detergents on soils. Chemosphere, 63, 1214-1221.

Rodriguez-Cruz, M. S., Sanchez-Martin, M. J., \& Sanchez-Camazano, M. (2004). Enhanced desorption of herbicides sorbed on soils by addition of Triton X-100. Journal Environ. Qual., 33, 920-929.

Rodriguez-Cruz, M. S., Sanchez-Martin, M. J., \& Sanchez-Camazano, M. (2006). Surfactant-enhanced desorption of atrazine and linuron residues as affected by aging of herbicides in soil. Arch. Environ. Contam. Toxicol., 50, $128-137$.

Rosen, M. J. (2004). Surfactants and interfacial phenomena. (4th ed.). New York: Wiley-Interscience.

Saichek, R. E., \& Reddy, K. R. (2004). Evaluation of surfactant/cosolvents for desorption/solubilization of phenanthrene in clayey soils. Intern. Journal Environ. Studies, Vol. 61, 5, 587-604.

Sanchez-Camazano, M., Rodriguez-Cruz, M. S, \& Sanchez-Martin, M. J. (2003). Evaluation of component characteristics of soil-surfactant-herbicide system that affect enhanced desorption of linuron and atrazine preadsorbed by soils. Environ. Sci. Technol., 37, 2758-2766.

Sanchez-Camazano, M., Sanchez-Martin, M. J., \& Rodriguez-Cruz, M. S. (2000). Sodium dodecylsulphate-enhanced desorption of atrazine: effect of surfactant concentration and of organic matter content of soils. Chemosphere, 41, 1301-1305. 
Sanchez-Martin, M. J., Rodriguez-Cruz, M. S., \& Sanchez-Camazano, M. (2003). Study of the desorption of linuron from soils to water enhanced by the addition of an anionic surfactant to soil-water system. Water Research, 37 , 3110-3117.

Smith, E., Smith, J., Naidu, R., \& Juhasz, A. L. (2004). Desorption of DDT from a contaminated soil using cosolvent and surfactant washing in batch experiments. Water, Air, and Soil Pollution, 151, 71-86.

Somasundaran, P., \& Huang, L. (2000). Adsorption aggregation of surfactants and their mixtures at solid-liquid interfaces. Advances in Colloid and Interface Science, 88, 179-208.

Sun, S., Inskeep, W. P., \& Boyd, S. A. (1995). Sorption of nonionic organic compounds in soil-water systems containing a micelle-forming surfactant. Environ. Sci. Technol., 29, 903-913.

Urum, K., \& Pekdemir, T. (2004). Evaluation of biosurfactants for crude oil contaminated soil washing. Chemosphere, 57, 1139-1150.

Urum, K., Grigson, S., Pekdemir, T., \& McMenamy, S. (2006). A comparison of the efficiency of different surfactants for removal of crude oil from contaminated soils. Chemosphere, 62, 1403-1410.

Urum, K., Pekdemir, T., \& Copur, M. (2004). Surfactant treatment of crude oil contaminated soils. Journal of Colloid and Interface Science, 276, 456-464.

Wang, W., \& Kwak. J. C. T. (1999). Adsorption at the alumina-water interface from mixed surfactant solutions. Colloids and Surfaces A: Physicochemical and Eng. Aspects, 156, 95-110.

Yang, K., Zhu, L., \& Zhao, B. (2005). Minimizing losses of nonionic and anionic surfactants to a montmorillonite saturated with calcium using their mixtures. Journal of Colloid and Interface Science, 291, 59-66.

Yu, H., Zhu, L., \& Zhou, W. (2007). Enhanced desorption and biodegradation of phenanthrene in soil-water systems with the presence of anionic/nonionic mixed surfactant. Journal of Hazardous Materials, 142, 354-361.

Zhang et al. (2005). Interaction of nonionic surfactant AEO9 with ionic surfactants. Journal Zhejiang Univ., SCI 6B, 6, 597-601.

Zhang, L., Somasundaran, P., Ososkov, V., \& Chou, C. C. (2001). Flotation of hydrophobic contaminants from soil. Colloids and Surfaces A: Physicochemical and Eng. Aspects, 177, 2-3, 235-246.

Zhang, R., \& Somasundaran, P. (2006). Advances in adsorption of surfactant and their mixtures at solid/solution interfaces. Advances in Colloid and Interface Science, 123-126, 213-229.

Zhao, B., \& Zhu, L. (2006). Solubilization of DNAPLs by mixed surfactant: synergism and solubilization capacity. Journal of Hazardous Materials, B136, 513-519.

Zhao, B., Chen, X., Zhu, K., \& Zhu, L. (2007). Micellar solubilization of TCE and PCE by mixed surfactant: effects of surfactant partitioning and DNAPL mixing. Colloids and Surfaces A: Physicochemical and Eng. Aspects, 296, 167-173.

Zhao, B., Zhu, L., \& Yang, K. (2006). Solubilization of DNAPLs by mixed surfactant: reduction in partitioning losses of nonionic surfactant. Chemosphere, 62, 772-779.

Zhao, B., Zhu, L., Li, W., \& Chen, B. (2005). Solubilization and biodegradation of phenanthrene in mixed anionic-nonionic surfactant solutions. Chemosphere, 58, 33-40.

Zheng, Z., \& Obbard, J. P. (2002). Evaluation of an elevated nonionic surfactant critical micelle concentration in a soil/aqueous system. Water Research, 36, 2667-2672.

Zhou, M., \& Rhue, R. D. (2000). Screening commercial surfactants suitable for remediation DNAPL source zones by solubilization. Environ. Sci. Technol., 34, 1985-1990.

Zhou, W., \& Zhu, L. (2004). Solubilization of pyrene by anionic-nonionic mixed surfactants. Journal of Hazardous Materials, B109, 213-220.

Zhou, W., \& Zhu, L. (2007). Enhanced desorption of phenanthrene from contaminated soil using anionic/nonionic mixed surfactant. Environmental Pollution, 147, 350-357.

Zhou, W., \& Zhu, L. (2005). Solubilization of Polycyclic Aromatic Hydrocarbons by Anionic-Nonionic Mixed Surfactants. Colloids and Surfaces A: Physiochem. Eng. Aspects, 255, 145-152.

Zhu, L. \& Feng, S. (2003). Synergistic solubilization of polycyclic aromatic hydrocarbons by mixed anionic-nonionic surfactants. Chemosphere, 53,459-467.

Zimmerman, J. B., Kibbey, T. C. G., Cowell, M. A., \& Hayes, K. F. (1999). Partitioning of ethoxylated nonionic surfactant into nonaqueous-phase organic liquids: influence on solubilization behavior. Environ. Sci. Technol., 33, 
$169-176$.

Zuidema, H. H., \& Waters, G. W. (1941). A Ring method for determination of interfacial tension. Industrial and Engineering Chemistry, Analytical Edition, Vol. 13, 312.

Table 1. Physicochemical properties of chemicals

\begin{tabular}{|c|c|c|c|c|c|c|}
\hline Chemical & $\begin{array}{c}\text { Structure/ } \\
\text { Composition }\end{array}$ & $\begin{array}{c}\mathrm{MW}^{\mathrm{a}} \\
\mathrm{g} / \mathrm{mol}\end{array}$ & $\begin{array}{c}\mathrm{CMC}^{\mathrm{b}}, \mathrm{mg} / \mathrm{L} \\
(\mathrm{mM} / \mathrm{L})\end{array}$ & $\mathrm{HLB}^{\mathrm{c}}$ & $\mathrm{D}^{\mathrm{d}}, \mathrm{g} / \mathrm{mL}$ & $\mathrm{BP}^{\mathrm{e}},{ }^{\circ} \mathrm{C}$ \\
\hline TX100 & $\mathrm{C}_{34} \mathrm{H}_{62} \mathrm{O}_{\mathrm{x}}(\mathrm{x}-11)$ & 646.37 & $\begin{array}{c}130-200 \\
(0.2-0.31)\end{array}$ & $13.5^{\S}$ & $1.070^{\#}$ & $270^{\#}$ \\
\hline SDS & $\mathrm{C}_{12} \mathrm{H}_{24} \mathrm{NaSO}_{4}$ & 288.4 & $\begin{array}{c}963-2420 \\
(3.32-8.4)\end{array}$ & $40^{\S}$ & $0.400^{\#}$ & - \\
\hline \multirow{2}{*}{ Sarapar147 } & $\begin{array}{c}95 \mathrm{wt} \% \\
\text { n-paraffin } \\
\text { and 5wt\% } \\
\text { iso-paraffin }\end{array}$ & $\mathrm{NA}$ & - & - & $0.773^{\#}$ & $258-293^{\#}$ \\
\hline
\end{tabular}

${ }^{\mathrm{a}}$ Molecular Weight; ${ }^{\mathrm{b}}$ Critical micelle Concentration; ${ }^{\mathrm{c}}$ Hydrophile-lipophile balance; ${ }^{\mathrm{d}}$ Density;

${ }^{\mathrm{e}}$ Boiling Point; ${ }^{\$}$ Zhou and Zhu (2004); ${ }^{\#}$ Provided by company; NA=Not Available.

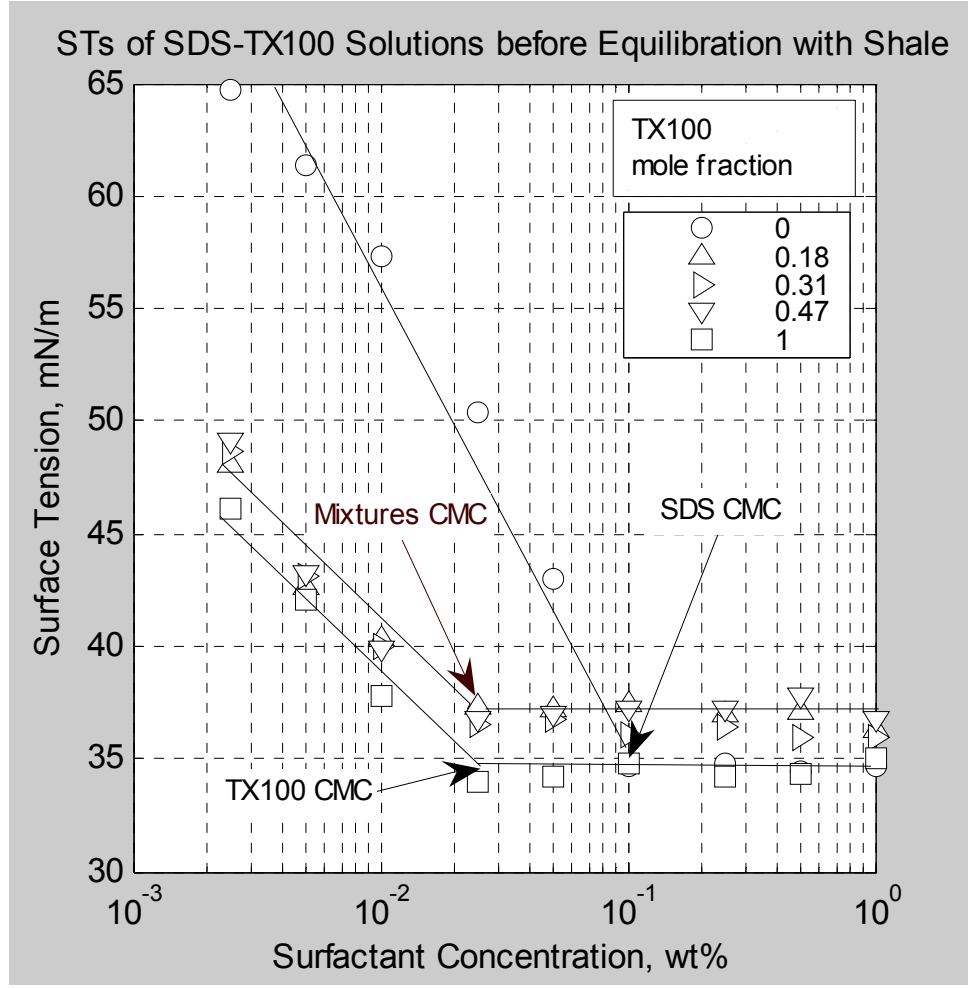

Figure 1. Surface Tension Curves for Pure Surfactants and Mixtures before Equilibration with Shale 


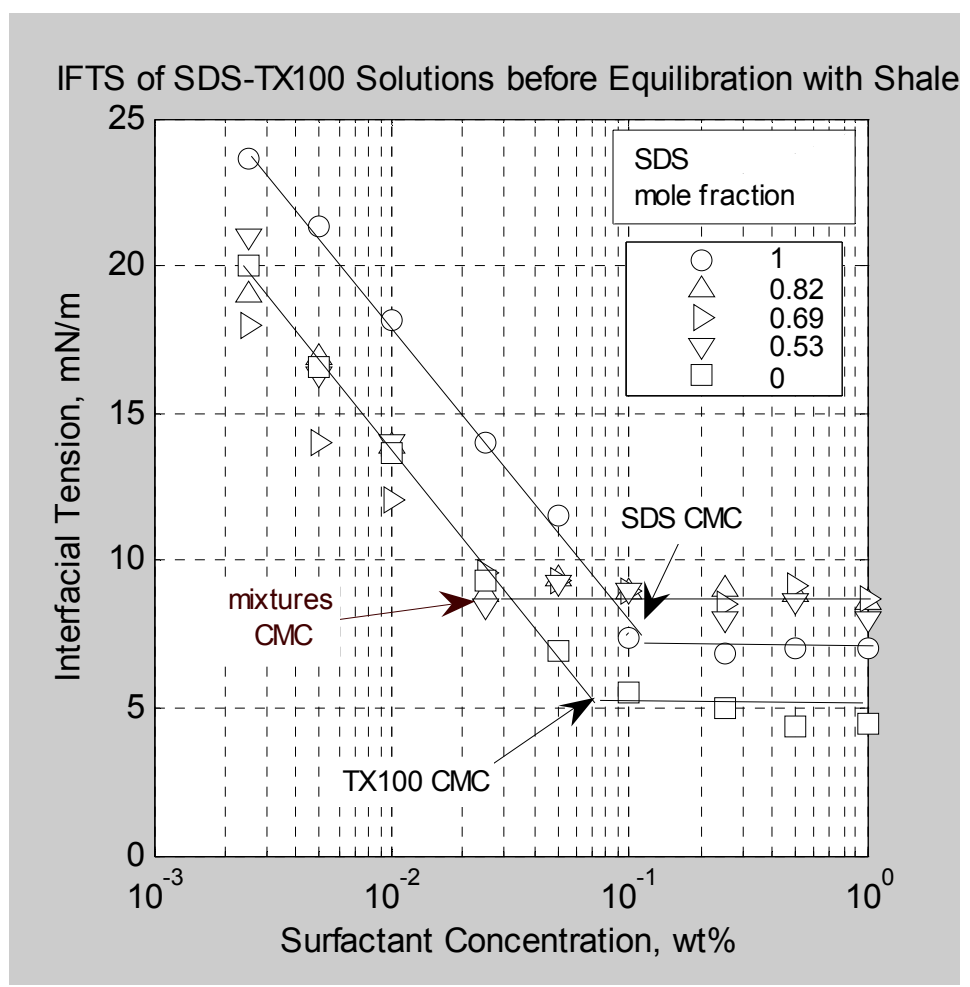

Figure 2. Interfacial Tension Curves for Pure Surfactants and Mixtures before Equilibration with Shale 